\title{
Bridging the Gap between the Human and Macaque Connectome: A Quantitative Comparison of Global Interspecies Structure-Function Relationships and Network Topology
}

\author{
Oscar Miranda-Dominguez, ${ }^{1,5 *}$ Brian D. Mills, ${ }^{1 \star}$ David Grayson, ${ }^{3}$ Andrew Woodall, ${ }^{4}$ Kathleen A. Grant, ${ }^{1,4}$ \\ Christopher D. Kroenke, ${ }^{1,2,4}$ and Damien A. Fair ${ }^{1,2}$ \\ ${ }^{1}$ Department of Behavioral Neuroscience and ${ }^{2}$ Advanced Imaging Research Center, Oregon Health and Science University, Portland, Oregon $97239,{ }^{3}$ Center \\ for Neuroscience, University of California, Davis, California 95616, ${ }^{4}$ Division of Neuroscience, Oregon National Primate Research Center, Beaverton, Oregon \\ 97006, and 5 Department of Biomedical Engineering, Tecnologico de Monterrey, Campus Monterrey, Nuevo Leon, Mexico 64849
}

Resting state functional connectivity MRI (rs-fcMRI) may provide a powerful and noninvasive "bridge" for comparing brain function between patients and experimental animal models; however, the relationship between human and macaque rs-fcMRI remains poorly understood. Here, using a novel surface deformation process for species comparisons in the same anatomical space (Van Essen, 2004, 2005), we found high correspondence, but also unique hub topology, between human and macaque functional connectomes. The global functional connectivity match between species was moderate to strong $(r=0.41)$ and increased when considering the top $15 \%$ strongest connections $(r=0.54)$. Analysis of the match between functional connectivity and the underlying anatomical connectivity, derived from a previous retrograde tracer study done in macaques (Markov et al., 2012), showed impressive structure-function correspondence in both the macaque and human. When examining the strongest structural connections, we found a $70-80 \%$ match between structural and functional connectivity matrices in both species. Finally, we compare species on two widely used metrics for studying hub topology: degree and betweenness centrality. The data showed topological agreement across the species, with nodes of the posterior cingulate showing high degree and betweenness centrality. In contrast, nodes in medial frontal and parietal cortices were identified as having high degree and betweenness in the human as opposed to the macaque. Our results provide: (1) a thorough examination and validation for a surface-based interspecies deformation process, (2) a strong theoretical foundation for making interspecies comparisons of rs-fcMRI, and (3) a unique look at topological distinctions between the species.

Key words: graph theory; macaque functional connectivity; network topology; resting state functional connectivity MRI; structure function relationships

\section{Introduction}

The development of clinically relevant animal models of mental illness will be crucial for the improvement and calibration of various therapeutic interventions. However, measures of human brain circuitry and function are difficult to model in nonhu-

Received Oct. 2, 2013; revised Feb. 21, 2014; accepted March 12, 2014.

Author contributions: 0.M.-D. and D.A.F. designed research; 0.M.-D., B.M., D.G., and A.W. performed research K.A.G., C.D.K., and D.A.F. contributed unpublished reagents/analytic tools; $0 . M .-D$. and B.M. analyzed data; B.M. and D.A.F. wrote the paper.

This work was supported by the National Institutes of Health (Grants R01 MH096773 and K99/R00 MH091238 to D.A.F.), McDonnell Foundation Collaborative Activity Award (220020256 to D.A.F., Site PI), Oregon Clinical and Translational Institute (D.A.F.), Programa de Profesores en el Extranjero (Tecnológico de Monterrey) Grants 11092, AA109431, and AA13510 (to 0.D.).

The authors declare no competing financial interests.

*0.M.-D. and B.D.M. are co-first authors.

Correspondence should be addressed to Damien Fair, PA-C, PhD, Behavioral Neuroscience Department, Oregon Health and Science University, 3181 SW Sam Jackson Park Road L470, Portland, Oregon 97239. E-mail: faird@ohsu.edu.

DOI:10.1523/JNEUROSCI.4229-13.2014

Copyright $\odot 2014$ the authors $\quad 0270-6474 / 14 / 345552-12 \$ 15.00 / 0$ man species in part due to neuroanatomical, particularly cortical, development and expansion. The nonhuman primate provides an excellent surrogate because key aspects of primate neuroanatomy have been extensively studied with sophisticated histological approaches. However, even with this benefit, it is not always clear that a given nonhuman primate model is accurately reflecting the same human condition for which it was designed. Ultimately, the translational potential of nonhuman primate models to examine human brain illness will benefit greatly from "bridging" measurements of brain function-measurements that can be obtained and compared directly between species.

One potential "bridge" measurement of brain function is resting state functional connectivity MRI ( $\mathrm{rs}-\mathrm{fcMRI}$ ), a noninvasive tool that measures correlated spontaneous brain activity (Biswal et al., 1995). As opposed to task-based fMRI, which is difficult to administer in many clinical populations and nonhuman primates, rs-fcMRI is task free. This makes rs-fcMRI an attractive 

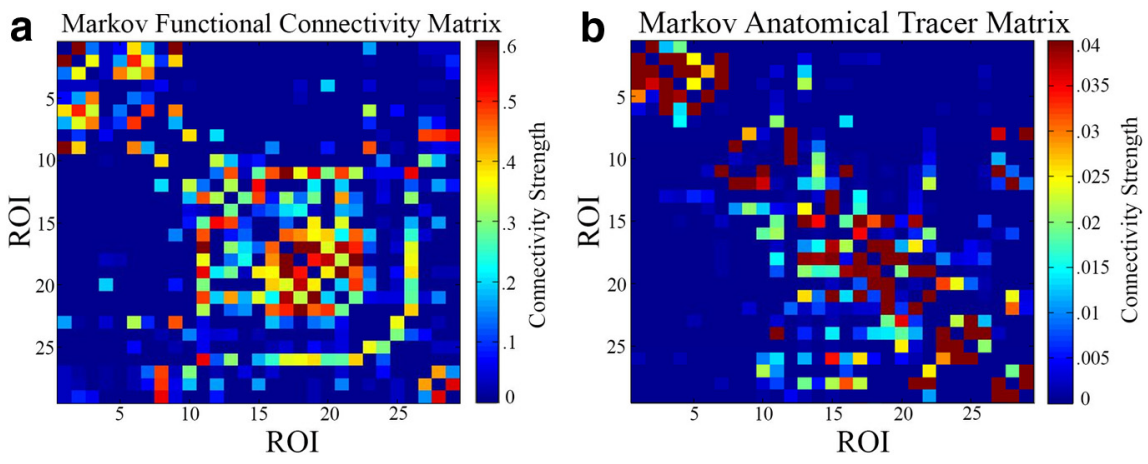

Figure 1. $\quad \boldsymbol{a}$, Functional connectivity matrix using the Markov atlas in the group of human subjects. $\boldsymbol{b}$, Anatomical connectivity matrix derived from a recent retrograde tracer study (Markov et al., 2012). For ease of visual comparison, we rearranged the ROI order for both matrices by community assignment. That is, community detection was run on the anatomical matrix using a method by Bullmore and Sporns (2009). Visually, one can see similarities in the functional and structural matrices. The family of ROC curves and regression analyses outlined in the Materials and Methods quantifies this relationship.

measure for translational research and may potentially provide a directly comparable tool for bridging the gap between human and macaque research. Indeed, qualitatively, macaque functional connectivity shows biologically plausible networks with at least partial resemblance to that of the human (Van Essen, 2005; Vincent et al., 2007; Margulies et al., 2009; Moeller et al., 2009; Vincent et al., 2010; Hutchison et al., 2011; Mantini et al., 2013; Sallet et al., 2013; Grayson et al., 2014a).

Although the promise of this approach is evident, there are a number of important considerations that need to be addressed. Namely, the strength and location of similarities and differences in interspecies connectivity is still an open question. Performing these comparisons in normative conditions is therefore essential for future studies examining functional connectivity in typical and disease models. Here, we use a surface-based interspecies registration technique described by Van Essen et al. (2004, 2005). This registration procedure allowed for direct comparisons to be made between species among several areal atlases (see Materials and Methods). Having comparable atlases in each species allows for both a visual (qualitative) and computational (quantitative) comparison between them. First, a seed-based analysis was used to make qualitative interspecies comparisons of rs-fcMRI networks. Next, the interspecies correspondence of whole-brain connectomes was assessed. Next, functional connectivity in the macaque and human was validated by comparing it with the underlying anatomical connectivity measured by retrograde tracers, the current gold standard in the field (Markov et al., 2012). Finally, interspecies comparisons were made on two widely used metrics of brain topology, node strength and betweenness centrality. This work provides a strong theoretical foundation for making interspecies comparisons of rs-fcMRI and provides a unique look at the differences in network "hub" topology between the species.

\section{Materials and Methods}

Human subjects and demographics. The human group consisted of 26 healthy subjects ( $26 \pm 4$ years, 15 females). All procedures were approved by the Institutional Review Board at Oregon Health and Science University. Participants were recruited through advertisements in the community, such as posted flyers, online ads, and the Oregon Health and Science University's clinical trials website. Potential participants were screened on the phone for initial eligibility. Exclusion criteria included a history of neurological trauma, a head injury with loss of consciousness, a medical condition that could affect cognition, or current substance abuse. Participants were also excluded for having a current depressive or manic epi- sode, a history of psychosis, bipolar disorder, learning disability, ADHD, current substance addiction, or for taking long-acting psychoactive medications. Informed consent was obtained for all participants.

Participants had to have normal use of both hands, be right-handed, and have normal or corrected-to-normal vision and normal hearing. Participants were also excluded if they had any contraindications to undergoing an MRI scan, such as pregnancy, metal in the body, or a history of claustrophobia. Eligible participants were then scheduled for an initial visit. At this visit, participants completed two semistructured clinical interviews, three modules from the Kiddie Schedule for Affective Disorders and Schizophrenia (Biederman et al., 1992) and one from the Schedule for Affective Disorders and Schizophrenia (Endicott and Spitzer, 1978) and the Structured Clinical Interview for DSM Disorders (First et al., 2012). Participants were excluded if those interviews revealed any of the psychiatric exclusion criteria outlined in the preceding paragraph.

Participants also completed an intelligence test (Wechsler Abbreviated Scale of Intelligence [WASI]; Wechsler, 1999) and an achievement test (Wide Range Achievement Test [WRAT-4]; Wilkinson and Robertson, 2006). These measures were used to assess IQ and to identify learning disabilities. Participants were excluded if they had an estimated full-scale IQ $<85$ or a suspected learning disability, as indicated by a difference of $>1.5$ SDs between cognitive functioning and achievement scores (as obtained in WASI and WRAT).

At their MRI visit, participants were screened for substance abuse with a urine toxicology screen administered at the beginning of the visit. The toxicology screen included tetrahydrocanabinol (THC), cocaine, opioids, amphetamine, and methamphetamine. Participants were excluded from completing the MRI scan if they tested positive for cocaine, opioids, amphetamines, or methamphetamines, but not if they tested positive for THC.

Human MRI acquisition. All MRI scans were performed on a Siemens 3T TIM-TRIO system. Structural images were obtained using a sagittal magnetization-prepared rapid gradient echo (MP-RAGE) 3D T1weighted sequence $\left(\mathrm{TR}=9.7 \mathrm{~ms}, \mathrm{TE}=4 \mathrm{~ms}\right.$, flip angle $=12^{\circ}, \mathrm{TI}=300$ $\mathrm{ms}$, voxel size $=1.25 \times 1 \times 1 \mathrm{~mm}$, slices $=128$ ). Functional images were obtained using a gradient-echo, echoplanar imaging (EPI) sequence sensitive to blood oxygen level-dependent (BOLD) contrast $(\mathrm{TR}=2000 \mathrm{~ms}$; $\mathrm{TE}=30 \mathrm{~ms} ; \mathrm{FOV}=240 \mathrm{~mm}^{3}$; flip angle $=90^{\circ}$ ). Full brain coverage was obtained with 33 contiguous, interleaved, $3.8 \mathrm{~mm}$ axial slices acquired parallel to the plane transecting the anterior and posterior commissure. Steady-state magnetization was assumed after 4 frames $(\sim 8 \mathrm{~s})$.

For the resting-state fMRI, participants completed either 2 scans consisting of 150 acquisitions (5 participants) or 1 scan of 600 acquisitions (22 participants). A longer scan was introduced to insure that sufficient volumes would be retained for data analysis after removal of volumes identified as having excessive movement.

Macaque subjects. The macaque group consisted of 11 male rhesus monkeys (Macaca mulatta; age $5 \pm 0.4$ years), which were chosen to have no common parents or grandparents, from the pedigreed Oregon $\mathrm{Na}-$ tional Primate Research Center breeding colony. For $\sim 6$ months before imaging, each monkey was individually housed in a stainless steel cage measuring $1.6 \times 0.8 \times 0.8 \mathrm{~m}$ (Allentown Caging) in a vivarium with $12 \mathrm{~h}$ light/dark cycle (with lights on at 7:00 A.M.) that was maintained at $21 \pm$ $1^{\circ} \mathrm{C}$ and $30-50 \%$ humidity. Each animal had visual, auditory, and olfactory access to other monkeys in the vivarium and limited physical access to a neighboring monkey. The monkeys were fed a diet of fresh fruit and $1 \mathrm{~g}$ of banana-flavored pellets in quantities sufficient to maintain a positive caloric intake.

All animal procedures were conducted in accordance with the Guidelines of the Committee on the Care and Use of Laboratory Animal Resources (National Health Council, Department of Health, Education, and Wel- 


\section{LVE Parcellation}
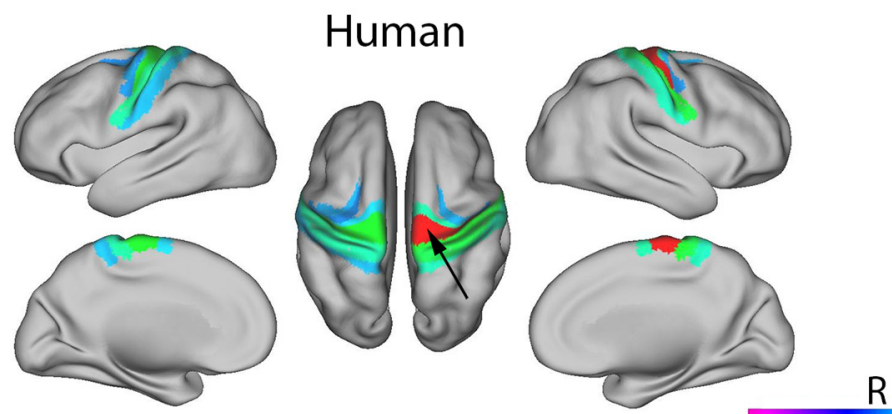

$\begin{array}{lllll}0.0 & 0.20 & 0.41 & 0.61 & 0.81\end{array}$

Top 5\% Connections
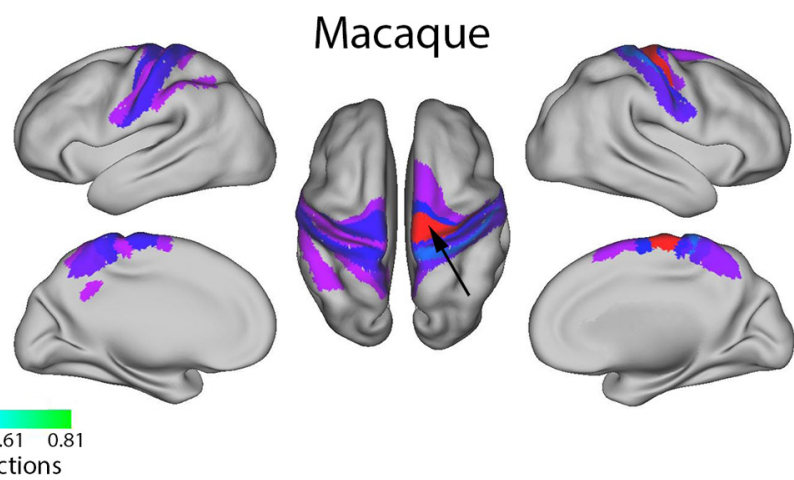

Markov Parcellation
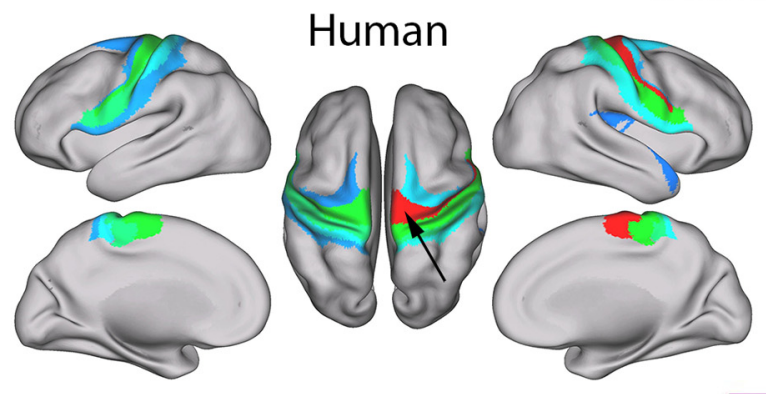

$\mathrm{R}$
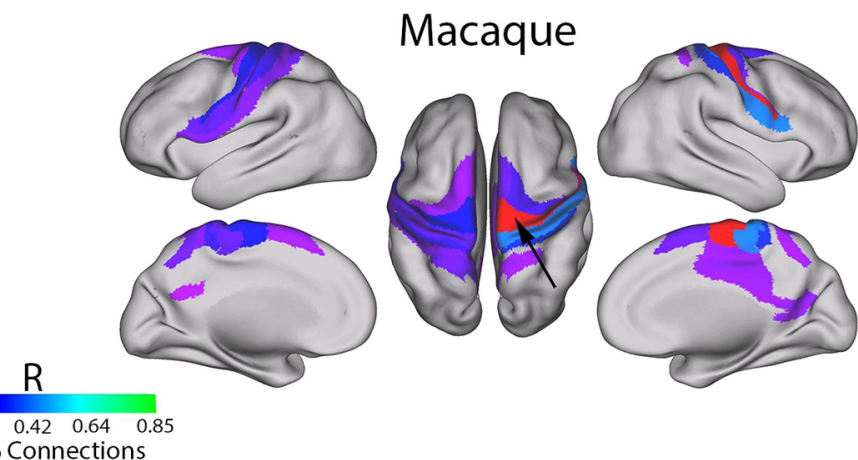

Figure 2. Qualitative interspecies comparisons of motor connectivity. Motor cortex resting state networks in the human and the macaque. The red regions with arrows pointing to them are the right motor cortex seed region. Resting state time series in this seed region were correlated with time series in each remaining ROI. Correlation coefficients between this seed region and each other $\mathrm{RO}$ are indicated by the color scale. Macaque connectivity is visualized on the human brain for comparison.

fare, ISBN 0-309-05377-3, revised 1996). Before their implementation, procedures were reviewed by the Institutional Animal Care and Use Committee of the Oregon National Primate Research Center and were in compliance with all local, state, and national regulations pertaining to the humane use of animal subjects.

Macaque MRI acquisition. Imaging was performed during a single session for each animal subject on a 3T Siemens Tim Trio scanner with a 15 -channel knee coil adapted for monkey head scanning. Subjects were sedated with an initial dose of ketamine $(5 \mathrm{mg} / \mathrm{kg})$, intubated, and maintained with $<1 \%$ isoflurane anesthesia for the duration of MRI procedures. Physiological monitoring throughout anesthesia included heart rate, respiration, and peripheral oxygen saturation. Data acquisition included four high-resolution T2-weighted structural images (TR $=3200$ $\mathrm{ms}, \mathrm{TE}=497 \mathrm{~ms} ; 0.5 \mathrm{~mm}^{2}$ in plane resolution, $1 \mathrm{~mm}$ slice thickness, 56 slices, FOV $=128 \times 128 \mathrm{~mm}$ ), which were averaged to improve the signal-to-noise ratio. A functional MRI scan lasting $30 \mathrm{~min}$ was then begun exactly $45 \mathrm{~min}$ after the time of ketamine administration (delaying the beginning of the acquisition as necessary to maintain the time from ketamine induction across all animals), using a gradient echo EPI sequence sensitive to BOLD contrast $(\mathrm{TR}=2070 \mathrm{~ms}, \mathrm{TE}=25 \mathrm{~ms}, \mathrm{FA}=$ $90^{\circ}, 1.5 \mathrm{~mm}^{3}$ voxels, 32 slices with interleaved acquisition, $\mathrm{FOV}=96 \times$ $96 \mathrm{~mm})$. A field map scan was acquired $(\mathrm{TR}=450 \mathrm{~ms}, \mathrm{TE}=5.19 \mathrm{~ms} / 7.65$ $\mathrm{ms}, \mathrm{FA}=60^{\circ}, 1.25 \times 1.25 \times 2 \mathrm{~mm}^{3}$ voxels, 40 slices, $\mathrm{FOV}=120 \times 120$ $\mathrm{mm}$ ) to correct for image distortion.

MRI general preprocessing. Human and macaque preprocessing were largely similar, with a few exceptions. Standard preprocessing steps included slice-timing correction, correction for odd versus even slice intensity differences attributable to interleaved acquisition without gaps, rigid-body correction for head motion, and rigid-body coregistration of the fMRI volumes with the high-resolution T2-weighted structural image (T1-weighted image used in humans). Intensity normalization was applied to each run to a whole-brain mode value gradient of 1000. All data were also transformed using 12-paramater affine registration to conform to a T2-weighted (or T1-weighted) atlas image. In the macaques, this atlas image was an average of 112 monkeys (http://brainmap. wisc.edu/monkey.html) in the widely used F99 space. In the humans, T1-weighted images were registered to the Talairach coordinate system. Atlas registration involved aligning each subject's T1-weighted image to a custom atlas-transformed (Lancaster et al., 1995) target T1-weighted template (711-2B) using a series of affine transforms (Michelon et al., 2003; Fox et al., 2005). The registration parameters obtained from each step allowed raw fMRI images to be transformed into atlas space, combining motion correction, field map unwarping (for macaques), and atlas transformation in one interpolation step.

Functional connectivity preprocessing. Functional connectivity preprocessing was largely identical for both groups. Several steps were also taken to prepare the data for connectivity analyses (Fox et al., 2005). These steps included spatial smoothing $(6 \mathrm{~mm}$ full width at half maximum smoothing for the human group and $3 \mathrm{~mm}$ full width at half maximum for the macaque), regression of 24 motion parameters obtained by rigid body head motion correction (Satterthwaite et al., 2013; Yan et al., 2013; Power et al., 2014), regression of nuisance signals (ventricular, white matter, and whole-brain signal) and their first order derivatives, and temporal band-pass filtering $(0.009 \mathrm{~Hz}<\mathrm{f}<0.08 \mathrm{~Hz})$. For macaques, ventricular and white matter masks were based on their corresponding regions in the INIA19 atlas (Rohlfing et al., 2012); human masks were applied as per Fox et al. (2005, 2009). Analyses were conducted with and without the regression of the global signal (i.e., whole-brain regression). As per Hallquist et al. (2013), the frequencies of nuisance regressors and fMRI data matched before nuisance regression, which was conducted before band-pass filtering. In addition, frame-by-frame spatial deviations of the acquisition time series were assessed using the temporal derivative of the time courses (i.e., frame displacement [FD]; Fair et al., 2012; Power et al., 2012). All analyses were conducted after the removal of frames with displacement $\mathrm{FD}>0.2 \mathrm{~mm}$. 

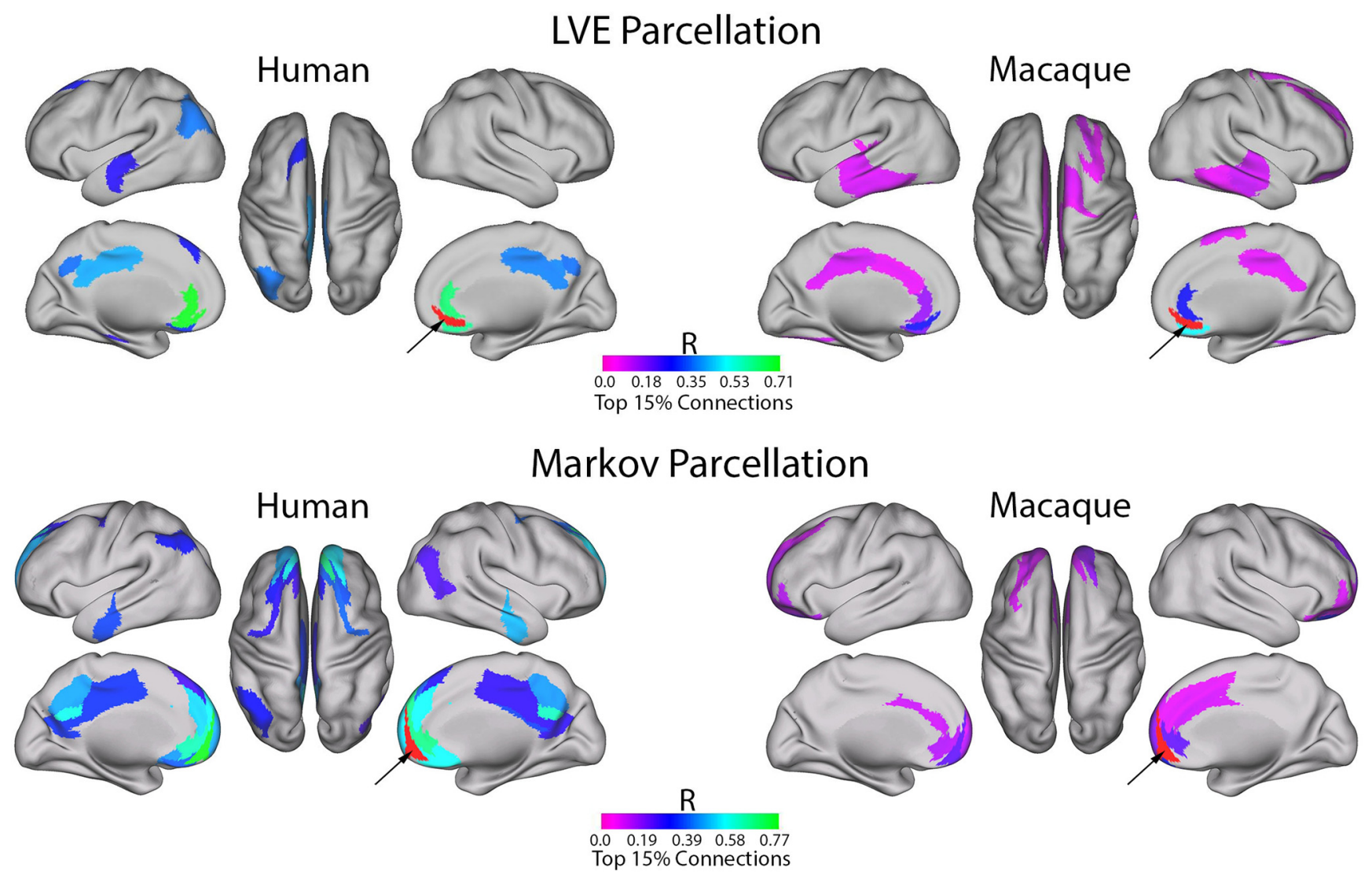

Figure 3. Qualitative interspecies comparisons of default mode connectivity. Functional connectivity is shown between a right anterior node of the default network, area 10 (shown in red), and the rest of the cortex in the human and the macaque. Correlation coefficients between the seed region and each other ROI are indicated by the color scale. Macaque connectivity is visualized on the human brain for comparison.

Human-macaque registration. Interspecies comparisons were made by surface-based atlas registration, which uses a spherical, landmark-based registration algorithm (Van Essen, 2004, 2005; Van Essen and Dierker, 2007). Landmarks for registration included a standard set of regions that are likely to be homologous across species, including visual areas V1, V2, MT, and frontal eye fields; primary auditory cortex; and olfactory, gustatory, somatosensory, and primary motor cortex (Astafiev et al., 2003; Van Essen, 2004). Differences in overall cortical shape are minimized by mapping each cortical surface to a standard configuration (i.e., a sphere), and then each sphere is registered to one another constrained by this set of homologous landmarks. Deformation from macaque to human cortex results in a large, nonuniform expansion of parietal, temporal, and frontal cortex and much less expansion in presumably conserved regions between species (i.e., V1, motor cortex, etc.). Landmark-based registration provides a powerful method for analyzing structural and functional organization between humans and macaques (Denys et al., 2004; Orban et al., 2004; Van Essen, 2005; Van Essen and Dierker, 2007). Each cortical parcellation was deformed from the macaque to the human PALS atlas using the deformation mapping provided by these procedures. Areal region of interest (ROI) deformations were done as part of the freely available CARET software package (http://brainvis.wustl.edu/wiki/index. php/Main_Page).

Four predefined cortical parcellations were used based on a set of brain areas delineated in previous work. These atlases included the FVE (Felleman and Van Essen, 1991), LVE (Lewis and Van Essen, 2000), Paxinos (Paxinos et al., 1999), and the Markov atlas (Markov et al., 2012). Surface ROIs for each area were converted to volume using caret software $(3 \mathrm{~mm}$ thickness in humans and $1.5 \mathrm{~mm}$ thickness in macaques).

Time series were computed for cortical ROIs in both species by averaging the signal intensity across all voxels within a given ROI at each time point. Cross-correlations were first computed between all cortical ROI pairs, yielding a correlation matrix of size $N \times N$ (where $N$ is the number of regions for a given parcellation) for each subject and for each parcellation. To combine correlation coefficients $(r)$ across subjects, the Schmidt-Hunter method for meta-analyses of $r$ values (i.e., averaged $r$ values) was used because it is more conservative than comparable methods (Field, 2001; Salvador et al., 2005; Dosenbach et al., 2007; Fair et al., 2007; Margulies et al., 2007). In the present study, only positive functional connections were considered.

Qualitative and quantitative human macaque comparisons. To compare functional connectivity patterns between species, qualitative comparisons were made in regions with classically well defined connectivity patterns. The motor system was examined by selecting a seed region in the right primary motor cortex. The default mode network was also examined by selecting a seed region in the ventral anterior cingulate cortex. Resting state connectivity time series in each of these seed regions were correlated with time series in all other regions. These data for each species was visualized on the human brain for comparison, with identical thresholds based on connection density. This was chosen instead of strict $r$ value threshold due to differences in the correlation distributions in the species. All analyses were performed with and without whole-brain regression.

A number of quantitative interspecies comparisons were also made. First, a global comparison of the similarity between human and macaque functional connectivity was made using simple linear regression. Scatter plots and regression lines show the relationship between connectivity matrices, where corresponding histograms represent the distribution of correlations in both humans and macaques after Fisher's $r$ to $z$ transformation.

Next, we assessed the correspondence between functional connectivity and the underlying structural connectivity derived from a recent retrograde tracer study done in macaques (Markov et al., 2012). This approach compares human and macaque functional connectivity with the macaque anatomical connectivity matrix (for an example, see Fig. 1). 
Because the Markov anatomical matrix consists of only one hemisphere, to allow for comparison, functional connectivity was computed as an average of both hemispheres and did not include interhemispheric connections. For the structure-function analyses, we used a subset of regions from the full Markov atlas. This structural connectivity matrix is based on a $29 \times 29$ areas, each of which received a tracer injection (Fig. 1b; Markov et al., 2012).

Our structure-function comparisons included both regression and receiver operator characteristic (ROC) curves analysis. Regression analysis compares anatomical and functional connectivity only considering nonzero anatomical connections. Next, to make weighted assessments of the match between structure and function, a family of ROC curves made comparisons across a range of connection strength thresholds (including both zero and nonzero anatomical connections). From here, the structural connectivity matrix was binarized 100 times using the 100 thresholds. In the first case, the strongest $1 \%$ of the connections were set to 1 and the remaining connections were set to 0 . Next, the top $2 \%$ of the strongest connections were set to 1 , leaving the remaining connections set to 0 . This approach was repeated, increasing the threshold $1 \%$ each time. Each of the resulting binary structural matrices was compared with the binary realizations of the functional matrix (Fig. $1 b$ ), which were created using 4000 different thresholds.

A family of ROC curves, each corresponding to a given threshold of the structural matrix, was generated, representing the number of true positives (a connection in both functional and structural matrices) and the number of false positives (a connection is a 1 in the functional matrix but a zero in the structural). One family of ROC curves compares macaque functional connectivity data with macaque anatomical connectivity and the other compares human functional connectivity with macaque anatomical connectivity.

All analyses were performed with and without the use of whole-brain regression. To further explore the effect of this preprocessing step on the strength and distribution of correlation coefficients, an additional analysis was run. Correlation coefficients for each connection were placed into bins of $10 \%$ for matrices processed both with and without whole-brain regression. The percentage of connections in each that remained in the same strength bin before and after whole-brain regression is plotted.

To assess similarities and differences in functional connectomes between species, we assessed node degree and between centrality, two cornerstone measurements of human brain organization (Bullmore and Sporns, 2009). Node degree is a measure of local network connectivity and identifies the most connected nodes (or ROIs) by counting the number of direct connections to all other nodes. A node with high degree will have strong, direct connections to many other nodes in the network (Wasserman and Faust, 1994; Bullmore and Sporns, 2009). Betweenness centrality is a measurement of a node's importance as a connecting hub between regions. It is calculated as the fraction number of the number of shortest paths that pass through a given node (Freeman, 1979; Bullmore and Sporns, 2009). Because these measurements are binary, connection weights are not included in either of these calculations. The MATLAB code used for degree and betweenness centrality can be obtained in the widely available brain connectivity toolbox (https://sites.google.com/ site/bctnet/measures/list; Rubinov and Sporns, 2010). Both measure-
Human - Macaque Functional Connectivity Match

\section{All Connections}

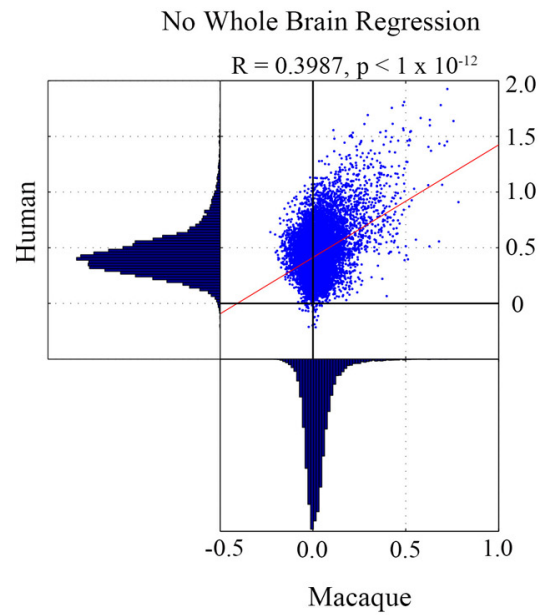

Top 15\% Connections

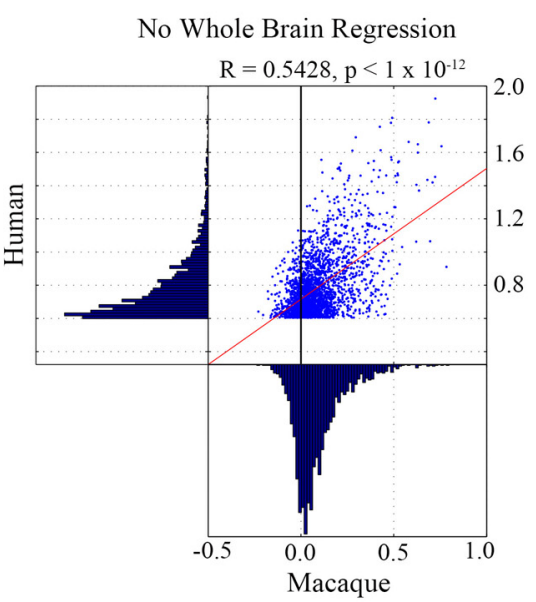

2.0

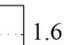

1.6 0.8

0.4

1.0

Figure 4. Interspecies functional connectivity match. Scatter plot and regression line show the relationship between human connections plotted against all corresponding macaque functional connections $(\boldsymbol{b})$. All values are considered after Fisher's $r$ to $z$ transformation and are based on the Markov atlas.

ments were computed based on the top $15 \%$ strongest positive functional connections for both species. Graph metrics are plotted on the same scale for humans and macaques, with the strongest values in red. Values are visualized on the human brain for ease of comparison. All graph metric analyses were performed after whole-brain regression. To assess the significance of differences between humans and macaques, a null distribution was built by randomizing the group labels on 10,000 permutations. For each randomized group, an average matrix was generated (i.e., Schmidt-Hunter method for meta-analyses) and differences between the two groups were calculated. Finally, the percentage of null values that exceeded the true observed value was calculated. A resulting two-tailed $p$-value for each ROI was then assessed for significance using FDR correction (Genovese et al., 2002) for 10\%, 15\%, and 20\% connection densities.

\section{Results}

\section{Qualitative comparisons of network connectivity}

\section{between species}

Qualitative comparisons of functional connectivity were made by reproducing two canonical networks, the primary motor network and the default mode network, in both humans and macaques. Figures 2 and 3 show connectivity patterns in the human and macaque for two parcellations (LVE and Markov) and both 


\section{Human - Macaque Functional Connectivity Match}

Top $15 \%$ Connections

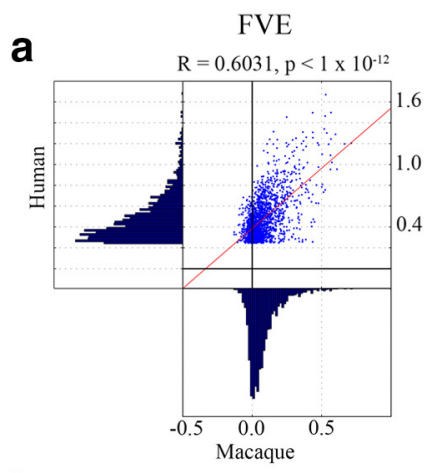

b

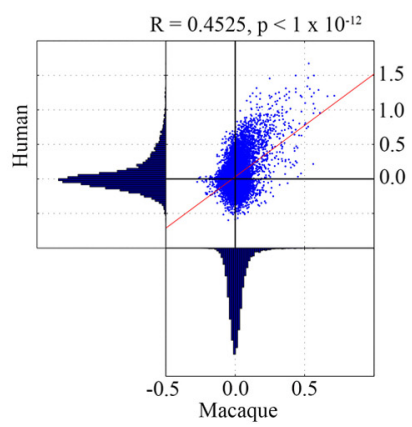

LVE

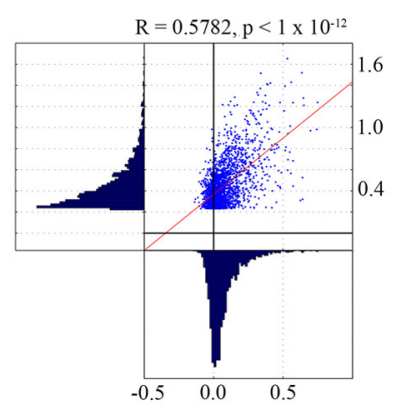

All Connections

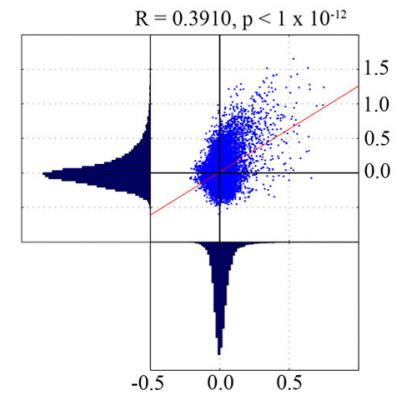

Markov
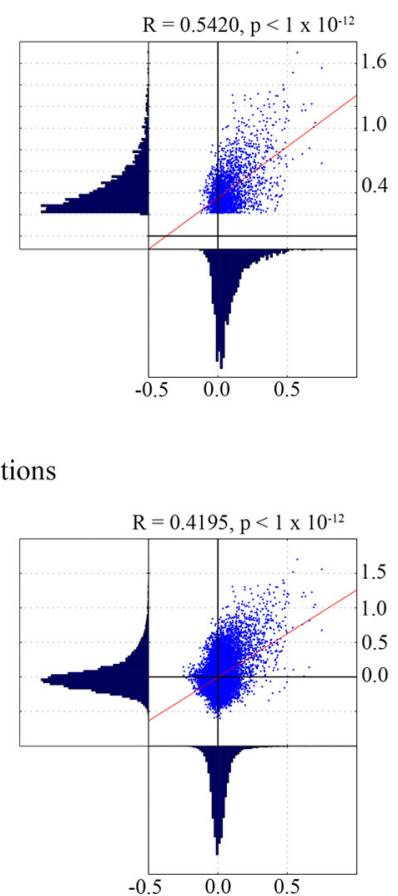

Paxinos
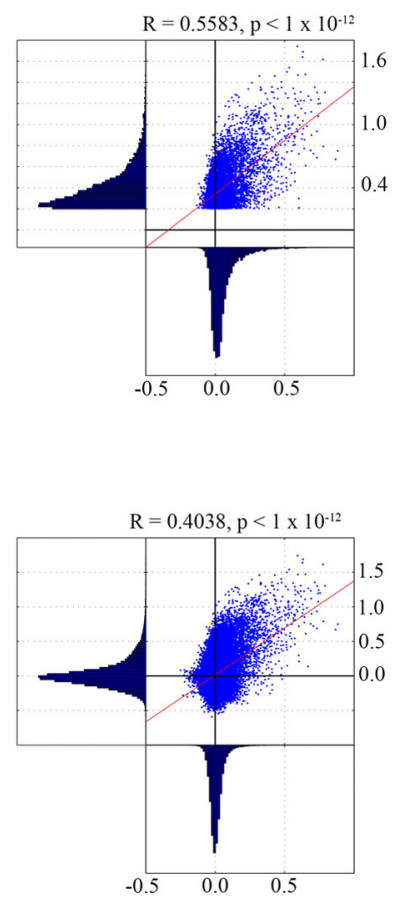

Figure 5. Human and macaque functional connectivity match using various parcellation schemes. $\boldsymbol{a}$, The top $15 \%$ of connections from the human functional connectivity matrix are compared with each corresponding connection in the macaque. $\boldsymbol{b}$, The relationship between human and macaque functional connectivity compared across the cortex. All comparisons shown are made after whole-brain regression and Fisher's $z$ transformation.

the macaque and human data are represented on a human surface atlas for comparability. Data are shown after whole-brain regression. Qualitatively, there appear to be both highly similar and unique representations across the species. For example, motor network connectivity is comparable across both species and for both parcellations. In this case, the degree of connectivity appears to be significantly weaker in the macaque, which may be due to anesthesia. In the default system, the findings were a bit more mixed and depended in part on the parcellation used. Here, using the LVE parcellation, we see a default system that resembles what has been identified in humans. However, connectivity does not extend to the entirety of the default system when using the Markov parcellations. In contrast, human connectivity in the default network is robust using each parcellation scheme.

\section{Interspecies comparisons of functional connectivity}

Scatter plots and linear regression analysis compare functional connectivity strength between humans and macaques. When considering all connections, macaque functional connectivity shows a significant relationship with human functional connectivity (Fig. 4a) and this is strengthened when considering the top $15 \%$ strongest connections (Fig. $4 b$ ). The corresponding histogram shows that humans and macaques have a somewhat unique distribution of correlation coefficients. The match between human and macaque functional connectivity is similar across each parcellation, but strongest for the FVE atlas (Fig. 5).

\section{Match between functional and anatomical connectivity}

Next, we assessed the relationship between functional connectivity and structural connectivity, as measured by a previous retrograde tracer study in macaques using the Markov anatomical parcellation (Markov et al., 2012). The Markov anatomical atlas provides a weighted measurement of anatomical connectivity between 29 unilateral brain regions. Here, we assess the correspondence between anatomical and functional connectivity to assist in validating the Van Essen deformation procedure and to estimate the structure-function relationships across species.

First, macaque functional connectivity was compared with macaque structural connectivity. As seen in Figure 6, when considering all structurally connected regions, functional connectivity in the macaque is significantly related to the underlying anatomical connectivity $\left(r=0.3465, p<1 \times 10^{-12}\right)$. Next, structure-function match across a range of thresholds was assessed using ROC curves. Interestingly, the correspondence between structural and functional connectivity was the greatest for the strongest structural connections at a level of nearly $80 \%$ of true positives and only $20 \%$ of false positives (Fig. 7).

Next, after applying Van Essen's (2004) surface deformation procedure, we were able to compare human functional connectivity with structural connectivity in the macaque. Remarkably, linear regression $\left(r=0.4186, p<1 \times 10^{-12}\right.$; Fig. 6) and the family of ROC curves show high correspondence between human functional connectivity and macaque anatomical connectivity measures, with an $\sim 80 \%$ match at the highest thresholds (Fig. 7). These results lend validation to both the biological underpinnings of the functional connectivity signal and the validity of Van Essen's (2004) macaque to human deformation procedure. 


\section{Effect of whole-brain regression}

Importantly, all analyses, regressions, and ROC curves are produced with and without whole-brain regression. Overall, using this preprocessing step improved many of the relationships examined. Specifically, functional connectivity match between species was significantly stronger after whole-brain regression regardless of the parcellation scheme $(p<0.001)$ when considering all functional connections. When considering the top $15 \%$ of connections, only the Paxinos atlas showed a significant improvement $(p<0.005)$. For the other atlases at this threshold, although structure-function correlation coefficients were stronger after whole-brain regression for both humans and macaques, the improvement was small and not significant. Further analysis showed that changes in the identity of the strongest functional connections after whole-brain regression were minimal. That is, the top $10 \%$ strongest correlations before its use remained binned as a top $10 \%$ strongest connection after using wholebrain regression $\sim 80 \%$ of the time (Fig. 8 ). A similar phenomenon was observed for the very weakest connections.

\section{Node degree and betweenness centrality comparison}

Node degree measures the importance of a given node to the overall network by assessing the number of regions to which a given ROI is connected. In both human and macaque, node degree is high in the posterior cingulate and surrounding areas. In humans, the frontal cortex (including area 10) shows high node degree. Similar findings are identified in the temporal cortices. When considering all connections, visual comparison shows that humans have a more distributed connection topology with regard to node degree, whereas, in macaques, connections are highly concentrated in the posterior, middle, and dorsal cingulate. These findings are not dependent on connection density (Fig. 9). Although the degree distribution of both human and macaque appears scale free in nature (as was described previously in humans; van den Heuvel et al., 2008), this phenomenon appears accentuated in the macaque (Fig. 10d).

Betweenness centrality is computed as the fraction of all shortest paths in a network that pass through a given node. Nodes with high values participate in a large number of shortest paths. Betweenness centrality can be conceptualized as the importance of an ROI as a connecting hub between regions. Both humans and macaques have the strongest betweeenness centrality in the posterior cingulate (and surrounding regions). Human and macaque betweenness centrality is similar, although humans more strongly recruit the frontoparietal attention system (Fig. 10).

\section{Discussion}

The present study compared rs-fcMRI measurements between humans and macaques on a number of levels. Using the Van Essen et al. (2004) surface-based deformation algorithm, macaque and human brains were examined whole-brain regression.

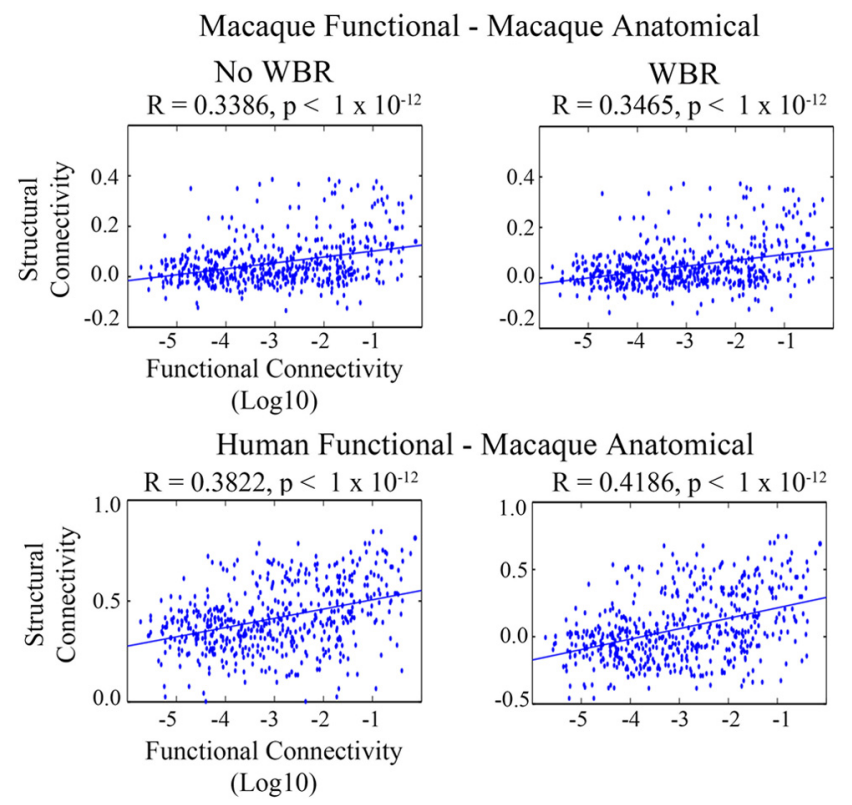

Figure 6. Match between functional and anatomical connectivity. Linear regression shows the relationship between functional and structural connectivity in regions that are anatomically connected. All values are Fisher's z transformed; functional connectivity values were then log transformed where applicable. Comparisons are performed both with and without whole-brain regression (WBR).

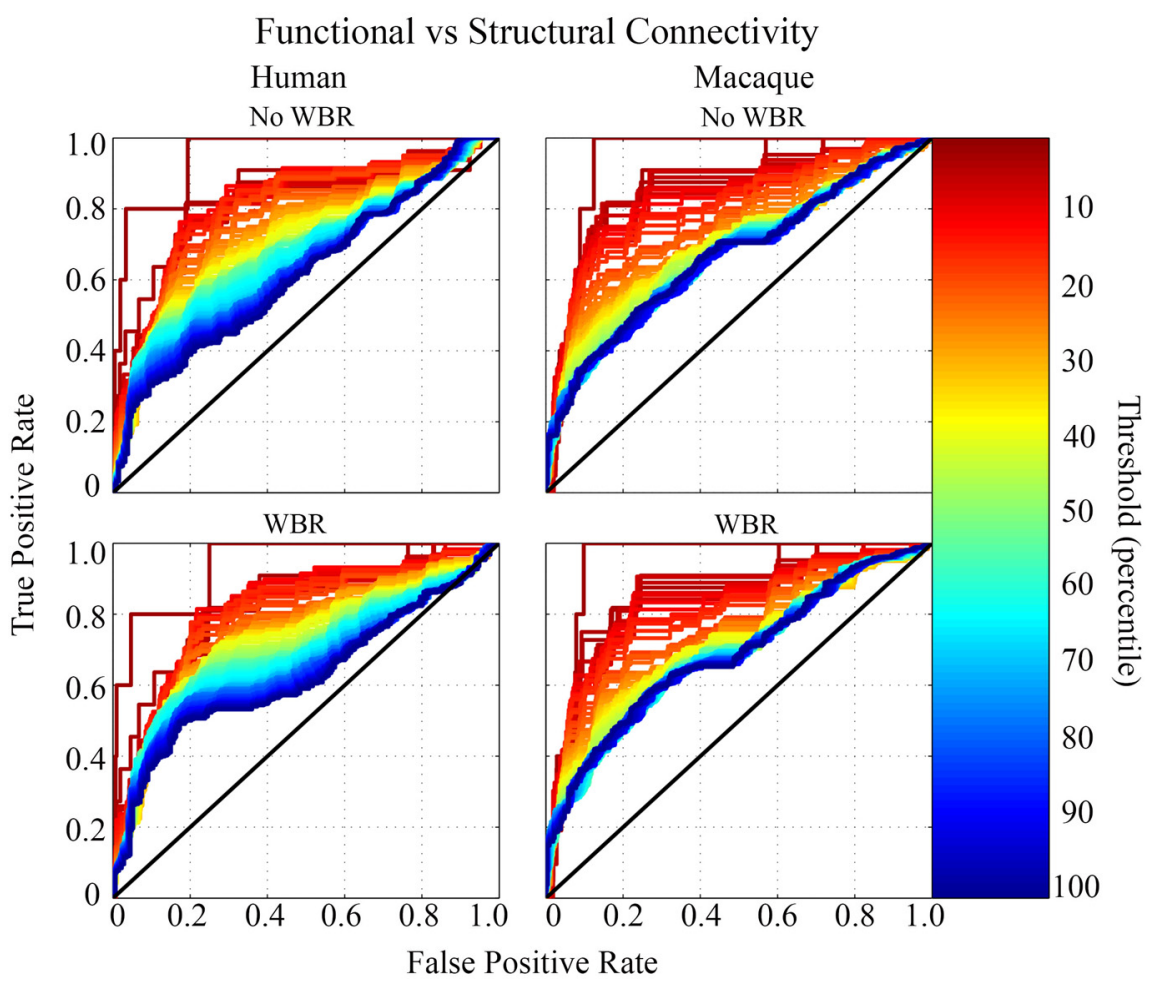

Figure 7. Family of ROC curves showing the match between human and macaque functional connectivity to the anatomical connectivity measured in the macaque. Each line represents an individual ROC curve for a given threshold. The diagonal line represents what would be expected by chance. The greater the area under the curve, the greater the proportion of matches between structural and functional matrices. Comparisons are performed both with and without whole-brain regression (WBR). The structure-function relationship is nonrandom, highest for the strongest structural connections, and slightly improved with

in the same atlas space, allowing for a direct comparison between the species. Our comparisons revealed high correspondence in functional connectivity between the species and marked similarity with regard to structure-function relation- 
ships. We also identified important similarities and differences with regard to large-scale brain topology. The work also highlights some important caveats with regard to processing and atlas selection.

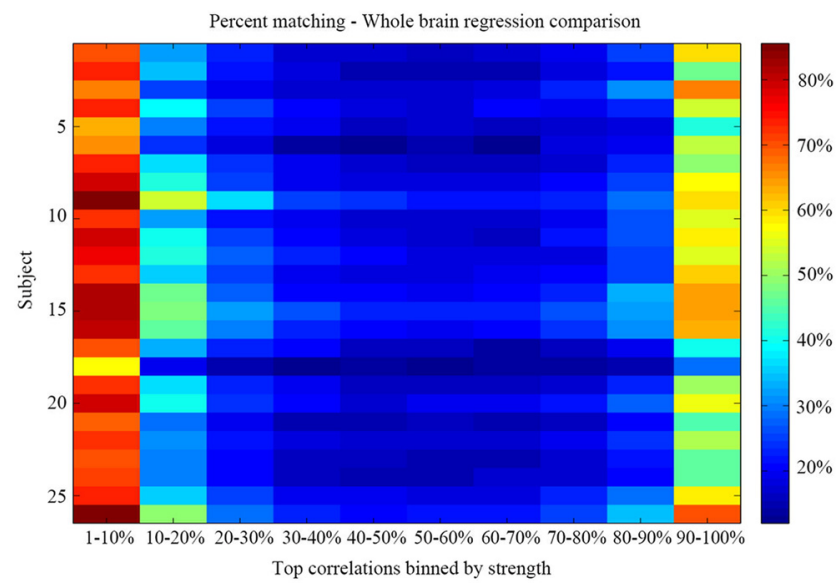

Figure 8. Effect of whole-brain regression on strength and distribution of correlation coefficients for each human participant. Correlation coefficients strengths were rank ordered and placed into $10 \%$ bins. The number of connections that remained in the same bin before and after whole-brain regression were quantified and plotted at the top. Approximately $80 \%$ of connections remain in the top $10 \%$ (1-10\% bin) after whole-brain regression. Importantly, similar correspondence is identified for the bottom bins.
Comparison of human and macaque functional connectivity Qualitatively, seed-based interspecies connectivity comparisons are dependent on both the region selection and the atlas used. As reported previously (Vincent et al., 2007; Hutchison et al., 2011), similar motor network connectivity was found in both humans and macaques. A comparison of default network connectivity between species also showed some similarities when placing a seed in an anterior node of the default system (region 10). However, this finding was partly dependent on the chosen atlas, highlighting the sensitivity of default identification to the parcellation scheme.

Sensitivity of findings to region selection is has been discussed previously (for a brief discussion, see Hagmann et al., 2012). The differences here could be influenced by several factors. As can be observed in Figure 4, the distributions of connectivity are unique across both species, with positive $r$ values in the macaque generally weaker than those in the human. This phenomenon is potentially secondary to the sedation state in the macaque versus the human and thus could lead to decreased sensitivity to the detection of this system. Similarly, it is also likely that some parcellations more accurately reflect the underlying areal demarcations for a given system. Along with increased noise in the macaque (potentially due to anesthesia or other acquisition or processing considerations), skewed areal boundaries for a given area would add to a reduction in signal-to-noise in the macaque and potentially result in weaker network visualization. In the human, in whom the connectivity signal is likely stronger due to the awake condition, the noise induced by skewed areal boundaries poten-

\section{Node Degree}

a
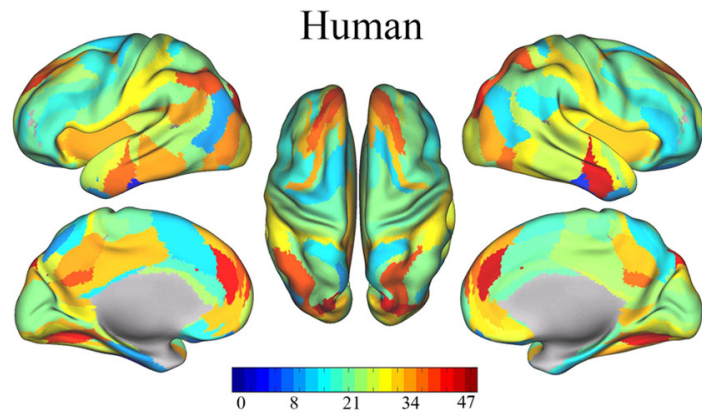

C

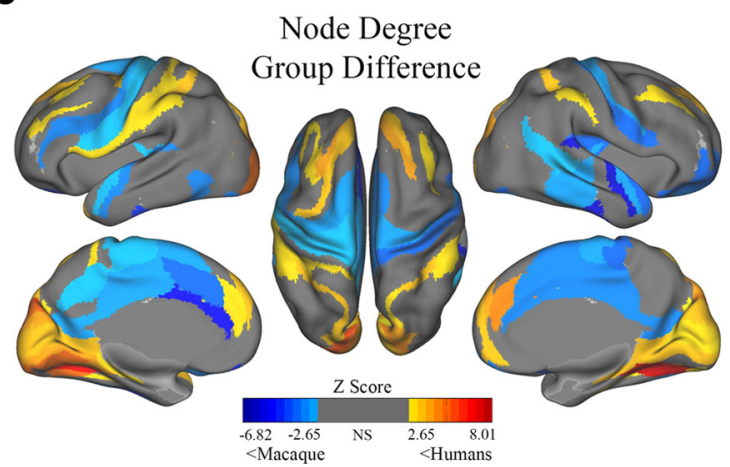

b

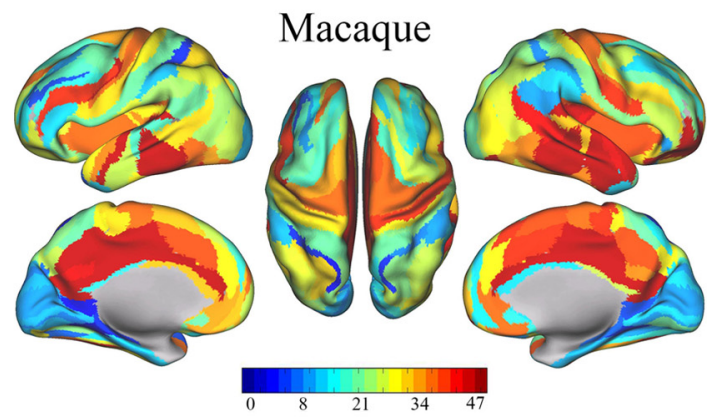

d

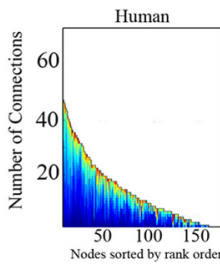

e

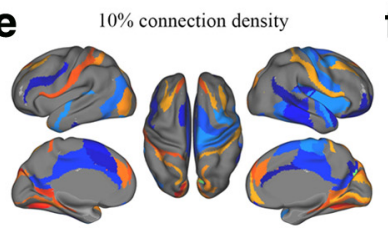

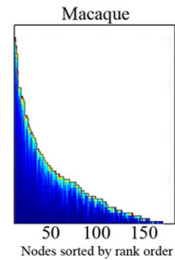

f $20 \%$ connection density

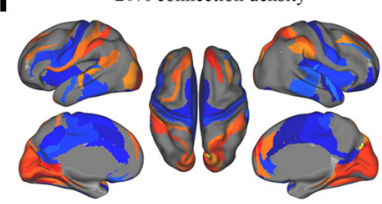

Figure 9. Interspecies comparison of node degree. $\boldsymbol{a}, \boldsymbol{b}$, Node degree, or the number of functional connections each ROI has to all other regions, is visualized in both species. For all analyses, both human and macaque matrices were thresholded to include only the top $15 \%$ of the strongest functional connections. Macaque connectivity is visualized on the human brain and scales are identical between species, allowing for direct comparison. Statistical comparison of human and macaque node degree are based on 10,000 permutations for $15 \%$ (c), $10 \%$ (e), and $20 \%$ ( $\boldsymbol{f}$ ) connection density. Blue colors represent regions where macaques have higher node degree and red colors represent areas where humans have higher node degree than macaques ( $p<0.05$, corrected). Notice that high degree nodes are clustered in the posterior cingulate in the macaque, whereas in humans, connections are spread to other networks such as the frontoparietal system. $\boldsymbol{d}$, Nodes have been reordered according to the number of connections to allow for comparison of degree distributions. Highly connected hubs in the macaques are clustered in only a few select regions that also have a greater number of max connections than humans (i.e., more "scale free"). Conversely, humans show a more distributed pattern in which highly connected hubs are spread throughout the cortex (i.e., less "scale free"). 


\section{Betweenness Centrality}

a

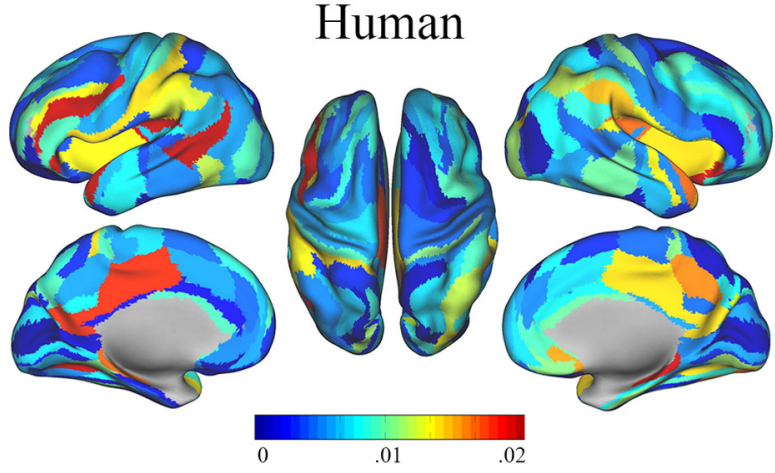

C

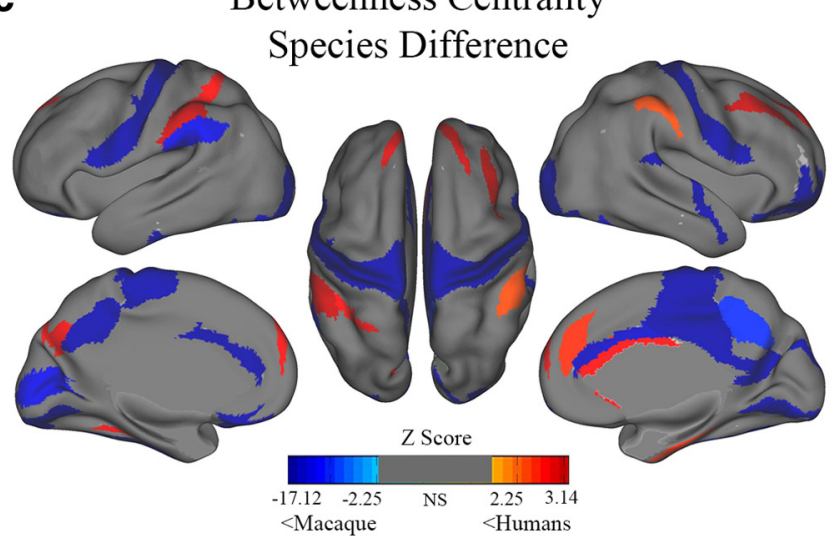

b
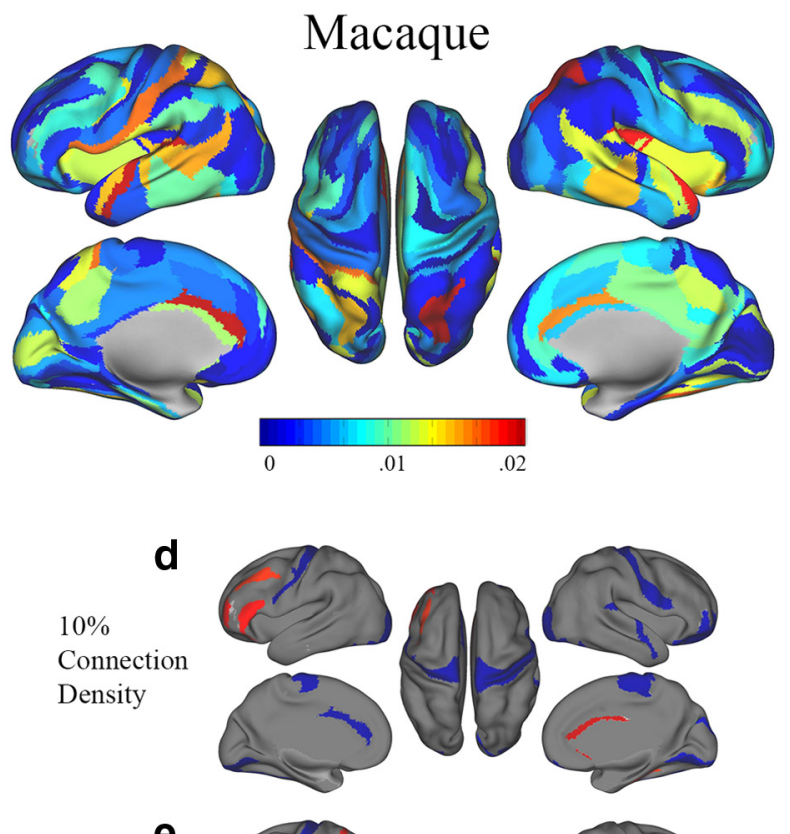

e
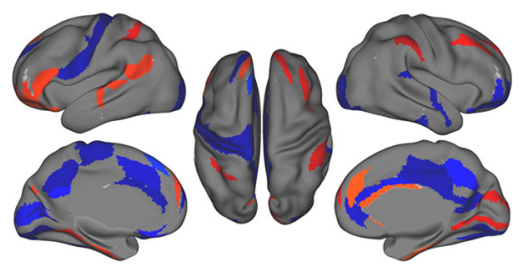

Figure 10. Interspecies comparison of betweeness centrality. $\boldsymbol{a}, \boldsymbol{b}$, Betweenness centrality, or the fraction of shortest paths that pass through a given R0l, is visualized in humans and macaques. Both human and macaque matrices were thresholded to include only the top $15 \%$ of the strongest functional connections. Macaque connectivity is visualized on the human brain and scales are identical between species, allowing for direct comparison. Statistical comparison of group differences in betweenness centrality based on 10,000 permutations for the 15\% (c), $10 \%$ (d), and $20 \%$ (e) strongest functional connections. Blue colors represent areas where macaques have higher betweenness centrality and red colors represent areas where humans have stronger centrality than macaques ( $p<0.05$, corrected). Noticethat humans have stronger centrality in frontoparietal regions, whereas macaque hubs are again centered preferentially in and around the posterior cingulate.

tially does not affect network patterns to the same extent. We also note the possibility that network differences between species could also arise from anesthesia affecting the overall network structure in the macaque (beyond simply reducing connection strength). A full characterization of the effects of anesthesia on network topology is an important subject for future work.

Our quantitative interspecies comparison showed there was a modest relationship between global human and macaque connectivity across the cortex. However, it appears that the distributions of connectivity values across the species are unique. We note that the extent of overlap between areal boundaries in the human and macaque is currently unknown and some of discrepancies may be influenced by such differences. Nonetheless, when considering only the strongest comparisons, the match between human and macaque connectivity dramatically improves. Therefore, this initial moderate relationship appears to correspond to a mismatch of low-probability connections and highlights the correspondence of highly probable functional connections between species.

Relationship between functional and anatomical connectivity We found a moderate relationship between the anatomical connectivity matrix (Markov et al., 2012) and the corresponding functional connectivity in both species, which appeared to be dependent on the strength of the anatomical connections. A family of ROC curves visualized and confirmed that the strongest underlying anatomical connections show the most correspondence with the functional connectivity. Illustrating this point, at most stringent thresholds, there is a $\sim 80 \%$ match between structural and functional connectivity with only an $\sim 20 \%$ falsepositive rate (Fig. 7). When considering all connections, the match is reduced, but still well above the level predicted purely by chance. Importantly, this match is apparent when comparing both human and macaque functional connectivity with the true macaque anatomical connectivity. In fact, the correspondence between human functional connectivity and anatomical connectivity was found to be slightly better than for the macaque functional connectivity. This phenomenon may again be attributed to the anesthesia in the macaques.

Although it has been shown that functional connectivity indeed reflects underlying structural connectivity, to date, studies have been limited. Such studies have used either indirect measures of anatomical connectivity (i.e., diffusion tensor imaging), only a limited number of subregions, or a lack of a global, quantitative comparison (Vincent et al., 2007; Hagmann et al., 2008; Greicius et al., 2009; van den Heuvel et al., 2009; Mars et al., 2011; Adachi et al., 2012; Shen et al., 2012). Our present study uses findings from a retrograde viral tracers study and shows that, 
across the cortex, axonal wiring indeed contributes to correlated functional activation.

The structure-function relationship was not perfect. It is known that functional connectivity is not simply driven by monosynaptic connections, as reflected in the tracer matrix, but also polysynaptic connections (Vincent et al., 2007; Honey et al., 2009; Iyer et al., 2013), which likely reduce the correspondence. Furthermore, unlike structural connectivity, which is relatively stable from day to day, functional connectivity shows less stability and can be more easily reconfigured (Bullmore and Sporns, 2009). Overall, the use of anatomical connectivity and the improvement in cross-species comparisons lend a basic validation for a structural neurobiological underpinning of the rs-fcMRI signal.

\section{Whole-brain regression improves interspecies functional connectivity match}

There is considerable disagreement on the appropriateness of whole-brain regression for resting-state processing (Fox et al., 2009; Murphy et al., 2009; Weissenbacher et al., 2009; Gotts et al., 2013).We found that interspecies correspondence in global functional connectivity was improved after regressing the global signal. However, this effect was parcellation and threshold dependent. The minor improvements seen here, an observation consistent with other reports (Fox et al., 2009; Keller et al., 2013), likely reflect the reduction in shared variance among regions due to noise and a true global signal (Schölvinck et al., 2010). Importantly, the rank order of the strongest connections does not overtly change whether one does or does not apply global regression (Fig. 8). However, investigators may wish to examine their data with and without whole-brain regression to determine whether a result is dependent on the processing decision.

\section{Interspecies comparison of node degree and betweenness centrality}

Last, we compared species on two widely used graph metrics for characterizing human brain topology: node degree and betweenness centrality. Consistent with previous studies, we found that humans showed high node degree and betweenness centrality in the posterior cingulate (Achard et al., 2006; Buckner et al., 2008; Hagmann et al., 2008). This suggests that the posterior cingulate is particularly important for integrating information across a wide range of modalities and is also an efficient route for passing information between systems.

Interestingly, the posterior cingulate shows the highest node degree and betweenness centrality in the macaque-even higher than in the human. In humans, the posterior cingulate, while focal, is not the only node with relatively high node degree and betweenness centrality. Rather, these nodes are distributed in frontal-parietal systems, the anterior insula, and medial frontal areas. The degree distribution is also unique between species (Fig. $9 d)$. In the macaque, top nodes have a greater number of functional connections than do those in humans. This suggests a more scale-free and perhaps more vulnerable network structure to targeted attack in the macaque. In stroke patients, selective damage to network hubs with high node degree is associated with severe cognitive deficits, in which damage to areas with fewer functional connections results in less severe deficits (Power et al., 2013). A network with more distributed hubs, such as observed in the humans, may reflect a more dynamic and resilient network structure (Grayson et al., 2014b). However, testing the robustness of our findings with alternative methods of defining hub architecture (van den Heuvel and Sporns, 2011; Hagmann et al., 2012;
Power et al., 2013; Grayson et al., 2014b) or assessing "connector" and "provincial" hub architecture (van den Heuvel and Sporns, 2011; Power et al., 2013) between species is an important avenue for future work.

\section{Resting state MRI as tool for translational medicine}

The present work represents an important step toward validating rs-fcMRI as a viable translational research tool to be used in nonhuman primates. Here, a baseline for comparing species is established, describing what can be expected at both the network and global connectivity level. Furthermore, it can be inferred that humans and macaques share a great deal of functional and anatomical connectivity. This is particularly true when considering the strongest functional connections that have the largest strength of overlap with underlying anatomy (up to $\sim 80 \%$ in both species). Such robust findings validate the biological basis for the rs-fcMRI signal and the surface-based human and macaque atlas deformation and registration algorithm (Van Essen, 2005). Further, we explore measurements of network organization that highlight potential regions of overlap, but also divergence, between species. Such information will help investigators target specific functional homologies between species and establish a solid basis for using rs-fcMRI as a bridge between human and macaque research.

\section{References}

Achard S, Salvador R, Whitcher B, Suckling J, Bullmore E (2006) A resilient, low-frequency, small-world human brain functional network with highly connected association cortical hubs. J Neurosci 26:63-72. CrossRef Medline

Adachi Y, Osada T, Sporns O, Watanabe T, Matsui T, Miyamoto K, Miyashita Y (2012) Functional connectivity between anatomically unconnected areas is shaped by collective network-level effects in the macaque cortex. Cereb Cortex 22:1586-1592. CrossRef Medline

Astafiev SV, Shulman GL, Stanley CM, Snyder AZ, Van Essen DC, Corbetta M (2003) Functional organization of human intraparietal and frontal cortex for attending, looking, and pointing. J Neurosci 23:4689-4699. Medline

Biederman J, Faraone SV, Keenan K, Benjamin J, Krifcher B, Moore C, Sprich-Buckminster S, Ugaglia K, Jellinek MS, Steingard R (1992) Further evidence for family-genetic risk factors in attention deficit hyperactivity disorder: patterns of comorbidity in probands and relatives in psychiatrically and pediatrically referred samples. Arch Gen Psychiatry 49:728-738. CrossRef Medline

Biswal B, Yetkin FZ, Haughton VM, Hyde JS (1995) Functional connectivity in the motor cortex of resting human brain using echo-planar MRI. Magn Reson Med 34:537-541. CrossRef Medline

Buckner RL, Andrews-Hanna JR, Schacter DL (2008) The brain's default network: anatomy, function, and relevance to disease. Ann N Y Acad Sci 1124:1-38. CrossRef Medline

Bullmore E, Sporns O (2009) Complex brain networks: graph theoretical analysis of structural and functional systems. Nat Rev Neurosci 10:186198. CrossRef Medline

Denys K, Vanduffel W, Fize D, Nelissen K, Sawamura H, Georgieva S, Vogels R, Van Essen D, Orban GA (2004) Visual activation in prefrontal cortex is stronger in monkeys than in humans. J Cogn Neurosci 16:1505-1516. CrossRef Medline

Dosenbach NU, Fair DA, Miezin FM, Cohen AL, Wenger KK, Dosenbach RA, Fox MD, Snyder AZ, Vincent JL, Raichle ME, Schlaggar BL, Petersen SE (2007) Distinct brain networks for adaptive and stable task control in humans. Proc Natl Acad Sci U S A 104:11073-11078. CrossRef Medline

Endicott J, Spitzer RL (1978) A diagnostic interview: the Schedule for Affective Disorders and Schizophrenia. Arch Gen Psychiatry 35:837-844. CrossRef Medline

Fair DA, Nigg JT, Iyer S, Bathula D, Mills KL, Dosenbach NU, Schlaggar BL, Mennes M, Gutman D, Bangaru S, Buitelaar JK, Dickstein DP, Di Martino A, Kennedy DN, Kelly C, Luna B, Schweitzer JB, Velanova K, Wang YF, Mostofsky S, et al. (2012) Distinct neural signatures detected for ADHD 
subtypes after controlling for micro-movements in resting state functional connectivity MRI data. Front Syst Neurosci 6:80. CrossRef Medline

Fair DA, Dosenbach NU, Church JA, Cohen AL, Brahmbhatt S, Miezin FM, Barch DM, Raichle ME, Petersen SE, Schlaggar BL (2007) Development of distinct control networks through segregation and integration. Proc Natl Acad Sci U S A 104:13507-13512. CrossRef Medline

Felleman DJ, Van Essen DC (1991) Distributed hierarchical processing in the primate cerebral cortex. Cereb Cortex 1:1-47. CrossRef Medline

Field AP (2001) Meta-analysis of correlation coefficients: a Monte Carlo comparison of fixed- and random-effects methods. Psychol Methods 6:161-180. CrossRef Medline

First MB, Spitzer RL, Gibbon M, Williams JB (2012) Structured Clinical Interview for DSM-IV Axis I Disorders (SCID-I), Clinician Version, Administration Booklet. Arlington, VA: American Psychiatric Publications.

Fox MD, Snyder AZ, Vincent JL, Corbetta M, Van Essen DC, Raichle ME (2005) The human brain is intrinsically organized into dynamic, anticorrelated functional networks. Proc Natl Acad Sci U S A 102:9673-9678. CrossRef Medline

Fox MD, Zhang D, Snyder AZ, Raichle ME (2009) The global signal and observed anticorrelated resting state brain networks. J Neurophysiol 101: 3270-3283. CrossRef Medline

Freeman LC (1979) Centrality in social networks conceptual clarification. Social Networks 1:215-239.

Genovese CR, Lazar NA, Nichols T (2002) Thresholding of statistical maps in functional neuroimaging using the false discovery rate. Neuroimage 15:870-878. CrossRef Medline

Gotts SJ, Saad ZS, Jo HJ, Wallace GL, Cox RW, Martin A (2013) The perils of global signal regression for group comparisons: a case study of autism spectrum disorders. Front Hum Neurosci 7.

Grayson DS, Kroenke CD, Neuringer M, Fair DA (2014a) Dietary omega-3 fatty acids modulate large-scale systems organization in the rhesus macaque brain. J Neurosci 34:2065-2074. CrossRef Medline

Grayson DS, Ray S, Carpenter S, Iyer S, Dias TG, Stevens C, Nigg JT, Fair DA (2014b) Structural and functional rich club organization of the brain in children and adults. PLoS One 9:e88297. CrossRef Medline

Greicius MD, Supekar K, Menon V, Dougherty RF (2009) Resting-state functional connectivity reflects structural connectivity in the default mode network. Cereb Cortex 19:72-78. CrossRef Medline

Hagmann P, Cammoun L, Gigandet X, Meuli R, Honey CJ, Wedeen VJ, Sporns O (2008) Mapping the structural core of human cerebral cortex. PLoS Biol 6:e159. CrossRef Medline

Hagmann P, Grant PE, Fair DA (2012) MR connectomics: a conceptual framework for studying the developing brain. Front Syst Neurosci 6:43. CrossRef Medline

Hallquist MN, Hwang K, Luna B (2013) The nuisance of nuisance regression: Spectral misspecification in a common approach to resting-state fMRI preprocessing reintroduces noise and obscures functional connectivity. Neuroimage 82C:208-225. CrossRef Medline

Honey CJ, Sporns O, Cammoun L, Gigandet X, Thiran JP, Meuli R, Hagmann P (2009) Predicting human resting-state functional connectivity from structural connectivity. Proc Natl Acad Sci U S A 106:2035-2040. CrossRef Medline

Hutchison RM, Leung LS, Mirsattari SM, Gati JS, Menon RS, Everling S (2011) Resting-state networks in the macaque at 7 T. Neuroimage 56: 1546-1555. CrossRef Medline

Iyer SP, Shafran I, Grayson D, Gates K, Nigg JT, Fair DA (2013) Inferring functional connectivity in MRI using Bayesian network structure learning with a modified PC algorithm. Neuroimage 75:165-175. CrossRef Medline

Keller CJ, Bickel S, Honey CJ, Groppe DM, Entz L, Craddock RC, Lado FA, Kelly C, Milham M, Mehta AD (2013) Neurophysiological investigation of spontaneous correlated and anticorrelated fluctuations of the BOLD signal. J Neurosci 33:6333-6342. CrossRef Medline

Lancaster JL, Glass TG, Lankipalli BR, Downs H, Mayberg H, Fox PT (1995) A modality-independent approach to spatial normalization of tomographic images of the human brain. Human Brain Mapping 3:209-223. CrossRef

Lewis JW, Van Essen DC (2000) Corticocortical connections of visual, sensorimotor, and multimodal processing areas in the parietal lobe of the macaque monkey. J Comp Neurol 428:112-137. CrossRef Medline

Mantini D, Corbetta M, Romani GL, Orban GA, Vanduffel W (2013) Evo- lutionarily novel functional networks in the human brain? J Neurosci 33:3259-3275. CrossRef Medline

Margulies DS, Kelly AM, Uddin LQ, Biswal BB, Castellanos FX, Milham MP (2007) Mapping the functional connectivity of anterior cingulate cortex. Neuroimage 37:579-588. CrossRef Medline

Margulies DS, Vincent JL, Kelly C, Lohmann G, Uddin LQ, Biswal BB, Villringer A, Castellanos FX, Milham MP, Petrides M (2009) Precuneus shares intrinsic functional architecture in humans and monkeys. Proc Natl Acad Sci U S A 106:20069-20074. CrossRef Medline

Markov NT, Ercsey-Ravasz MM, Ribeiro Gomes AR, Lamy C, Magrou L, Vezoli J, Misery P, Falchier A, Quilodran R, Gariel MA, Sallet J, Gamanut R, Huissoud C, Clavagnier S, Giroud P, Sappey-Marinier D, Barone P, Dehay C, Toroczkai Z, Knoblauch K, et al. (2012) A weighted and directed interareal connectivity matrix for macaque cerebral cortex. Cereb Cortex 24:17-36. CrossRef Medline

Mars RB, Jbabdi S, Sallet J, O'Reilly JX, Croxson PL, Olivier E, Noonan MP, Bergmann C, Mitchell AS, Baxter MG, Behrens TE, Johansen-Berg H, Tomassini V, Miller KL, Rushworth MF (2011) Diffusion-weighted imaging tractography-based parcellation of the human parietal cortex and comparison with human and macaque resting-state functional connectivity. J Neurosci 31:4087-4100. CrossRef Medline

Michelon P, Snyder AZ, Buckner RL, McAvoy M, Zacks JM (2003) Neural correlates of incongruous visual information: an event-related fMRI study. Neuroimage 19:1612-1626. CrossRef Medline

Moeller S, Nallasamy N, Tsao DY, Freiwald WA (2009) Functional connectivity of the macaque brain across stimulus and arousal states. J Neurosci 29:5897-5909. CrossRef Medline

Murphy K, Birn RM, Handwerker DA, Jones TB, Bandettini PA (2009) The impact of global signal regression on resting state correlations: are anticorrelated networks introduced? Neuroimage 44:893-905. CrossRef Medline

Orban GA, Van Essen D, Vanduffel W (2004) Comparative mapping of higher visual areas in monkeys and humans. Trends Cogn Sci 8:315-324. CrossRef Medline

Paxinos G, Huang XF, Toga AW (1999) The rhesus monkey brain in stereotaxic coordinates 2000 ed. San Diego: Academic.

Power JD, Barnes KA, Snyder AZ, Schlaggar BL, Petersen SE (2012) Spurious but systematic correlations in functional connectivity MRI networks arise from subject motion. Neuroimage 59:2142-2154. CrossRef Medline

Power JD, Schlaggar BL, Lessov-Schlaggar CN, Petersen SE (2013) Evidence for hubs in human functional brain networks. Neuron 79:798-813. CrossRef Medline

Power JD, Mitra A, Laumann TO, Snyder AZ, Schlaggar BL, Petersen SE (2014) Methods to detect, characterize, and remove motion artifact in resting state fMRI. Neuroimage 84:320-341. CrossRef Medline

Rohlfing T, Kroenke CD, Sullivan EV, Dubach MF, Bowden DM, Grant KA, Pfefferbaum A (2012) The INIA19 template and NeuroMaps atlas for primate brain image parcellation and spatial normalization. Front Neuroinform 6:27. CrossRef Medline

Rubinov M, Sporns O (2010) Complex network measures of brain connectivity: uses and interpretations. Neuroimage 52:1059-1069. CrossRef Medline

Sallet J, Mars RB, Noonan MP, Neubert FX, Jbabdi S, O’Reilly JX, Filippini N, Thomas AG, Rushworth MF (2013) The organization of dorsal frontal cortex in humans and macaques. J Neurosci 33:12255-12274. CrossRef Medline

Salvador R, Suckling J, Coleman MR, Pickard JD, Menon D, Bullmore E (2005) Neurophysiological architecture of functional magnetic resonance images of human brain. Cereb Cortex 15:1332-1342. CrossRef Medline

Satterthwaite TD, Elliott MA, Gerraty RT, Ruparel K, Loughead J, Calkins ME, Eickhoff SB, Hakonarson H, Gur RC, Gur RE, Wolf DH (2013) An improved framework for confound regression and filtering for control of motion artifact in the preprocessing of resting-state functional connectivity data. Neuroimage 64:240-256. CrossRef Medline

Schölvinck ML, Maier A, Ye FQ, Duyn JH, Leopold DA (2010) Neural basis of global resting-state fMRI activity. Proc Natl Acad Sci U S A 107:1023810243. CrossRef Medline

Shen K, Bezgin G, Hutchison RM, Gati JS, Menon RS, Everling S, McIntosh AR (2012) Information processing architecture of functionally defined clusters in the macaque cortex. J Neurosci 32:17465-17476. CrossRef Medline 
van den Heuvel MP, Sporns O (2011) Rich-club organization of the human connectome. J Neurosci 31:15775-15786. CrossRef Medline

van den Heuvel MP, Stam CJ, Boersma M, Hulshoff Pol HE (2008) Smallworld and scale-free organization of voxel-based resting-state functional connectivity in the human brain. Neuroimage 43:528-539. CrossRef Medline

van den Heuvel MP, Mandl RC, Kahn RS, Hulshoff Pol HE (2009) Functionally linked resting-state networks reflect the underlying structural connectivity architecture of the human brain. Hum Brain Mapp 30:31273141. CrossRef Medline

Van Essen DC (2004) Surface-based approaches to spatial localization and registration in primate cerebral cortex. Neuroimage 23:S97-S107. CrossRef Medline

Van Essen DC (2005) Surface-based comparisons of macaque and human cortical organization. In: From monkey brain to human brain (Dehaene S, Duhamel JR, Hauser MD, Rizzolatti G, eds.), pp 3-19. Cambridge, MA: MIT.

Van Essen DC, Dierker DL (2007) Surface-based and probabilistic atlases of primate cerebral cortex. Neuron 56:209-225. CrossRef Medline

Vincent JL, Patel GH, Fox MD, Snyder AZ, Baker JT, Van Essen DC, Zempel
JM, Snyder LH, Corbetta M, Raichle ME (2007) Intrinsic functional architecture in the anesthetized monkey brain. Nature 447:83-86. CrossRef Medline

Vincent JL, Kahn I, Van Essen DC, Buckner RL (2010) Functional connectivity of the macaque posterior parahippocampal cortex. J Neurophysiol 103:793-800. CrossRef Medline

Wasserman S, Faust K (1994) Social network analysis: methods and applications. New York: Cambridge UP.

Wechsler D (1999) Wechsler abbreviated scale of intelligence, Ed 3. San Antonio: The Psychological Corporation.

Weissenbacher A, Kasess C, Gerstl F, Lanzenberger R, Moser E, Windischberger C (2009) Correlations and anticorrelations in resting-state functional connectivity MRI: a quantitative comparison of preprocessing strategies. Neuroimage 47:1408-1416. CrossRef Medline

Wilkinson GS, Robertson G (2006) Wide Range Achievement Test (WRAT4). Lutz, FL: Psychological Assessment Resources.

Yan CG, Cheung B, Kelly C, Colcombe S, Craddock RC, Di Martino A, Li Q, Zuo XN, Castellanos FX, Milham MP (2013) A comprehensive assessment of regional variation in the impact of head micromovements on functional connectomics. Neuroimage 76:183-201. CrossRef Medline 